\title{
Assessment of Wound Dehiscence in Smead Jones (Far - Near Near - Far) Technique of Midline Abdominal Wound Closure - An Observational Study
}

\author{
Sahil Khajuriaํㅜ, Mohinder Kumar², Anshuka ${ }^{3}$, Shadi Lal Kachroo ${ }^{4}$ \\ ${ }^{1}$ Department of Surgery GMC Jammu, Jammu and Kashmir, India. ${ }^{2}$ Department of Surgery GMC Jammu, \\ Jammu and Kashmir, India. ${ }^{3}$ Department of Orthodontics VSPM College Nagpur, Maharashtra, India. \\ ${ }^{4}$ Department of Surgery GMC, Jammu, Jammu and Kashmir, India.
}

\section{ABSTRACT}

\section{BACKGROUND}

We wanted to evaluate the occurrence of wound dehiscence in class III and class IV wounds, that are contaminated, with an interrupted, far-near near-far technique (Smead Jones technique) of midline abdominal wound closure and study the occurrence of wound dehiscence in patients requiring laparotomy having high risk / co-morbid states.

\section{METHODS}

A total of 100 cases was selected and abdominal wound closure was done by Smead Jones technique using polypropylene suture No. 1. The Smead Jones sutures are double loop far-near, near-far applied to linea alba. All the patients were started on intravenous antibiotics. The wound was managed by daily antiseptic dressings. Postoperatively, the patients were followed up daily for 10 days and then once every 15 days up to 6 weeks to check for any disruption in suture line.

\section{RESULTS}

All patients were operated under general anaesthesia. The incision used was vertical midline. Majority of the cases were perforation peritonitis and intestinal obstruction (malignant or tubercular). Out of 100 patients, 76 patients had dirty wound, 10 had contaminated and 14 patients had clean contaminated wounds. Out of 100 patients, 2 patients had wound dehiscence. Dehiscence was observed on $7^{\text {th }}$ post-operative day in one patient who was a case of perforation peritonitis due to duodenal ulcer perforation, who presented late in emergency after four days of symptoms. Secondary suturing was done after proper build up and was discharged on $16^{\text {th }}$ postoperative day of his index surgery.

\section{CONCLUSIONS}

From the present study, it can be concluded that the technique of closure of contaminated and dirty wounds is an important factor in the final outcome of the emergency laparotomy. In such cases burst abdomen can be reduced using Smead Jones (far-near near-far) interrupted technique of midline abdomen wound closure using non-absorbable polypropylene suture.

\section{KEY WORDS}

Smead Jones Sutures, Contaminated Wounds, Dirty Wounds, Wound Dehiscence

\author{
Corresponding Author: \\ Dr. Sahil Khajuria. \\ qtr/e9, Medical Enclave Near KC Theatre, \\ Bakshi Nagar, Jammu - 180001 \\ Jammu and Kashmir, India. \\ E-mail: sahilkhajuria71@gmail.com
}

DOI: $10.14260 /$ jemds/2020/584

How to Cite This Article: Khajuria S Kumar M, Anshuka, et al. Assessment of wound dehiscence in smead jones (far-near near - far) technique of midline abdominal wound closure - an observational study. J Evolution Med Dent Sci 2020;9(37):2686-2689, DOI: $10.14260 /$ jemds/2020/584

Submission 03-06-2020,

Peer Review 03-08-2020,

Acceptance 10-08-2020,

Published 14-09-2020.

Copyright (C) 2020 JEMDS. This is an open access article distributed under Creative Commons Attribution License [Attribution 4.0 International (CC BY 4.0)] 


\section{BACKGROUND}

Wound scar is the signature of a surgeon. Incisional wound is the product and responsibility of the surgeon. Surgeons come across the problem of wound infection and dehiscence day in and day out. Disruption of abdominal incision is a serious, sometimes catastrophic event, marring what might otherwise have been a brilliant surgical achievement. Various approaches have been employed in abdominal surgeries to access the abdominal cavity. Different types of incisions can be employed as per the type of surgery. Vertical midline incision is the most common incision employed in emergency laparotomies.

Abdominal wound dehiscence is a common complication of emergency laparotomy globally, which carries with it a substantial morbidity. In addition, there is an increase in the cost of care, both in terms of increased hospital stay as well as cost in managing its complications. Acute wound failure (wound dehiscence or a burst abdomen) refers to postoperative separation of the abdominal musculo-aponeurotic layers. It most often develops 7 to 10 days post-operatively but may occur any time after surgery, to more than 20 days.

Wound dehiscence can be attributed to multiple factors. ${ }^{1}$ It can be due to technical errors, like placing sutures too close to the edge, too far apart, or under too much tension. Local factors such as hematoma and infection can also cause burst abdomen. Further an increase in intra-abdominal pressure (IAP) can lead to burst abdomen or wound dehiscence.

Out of numerous etiological factors causing wound dehiscence, the technique of closure of abdomen and the suture material used has an important bearing on the final outcome of the wound. ${ }^{2}$

In the past, most techniques of incision closure have used interrupted sutures. ${ }^{3}$ The closure of laparotomy wound by interrupted mass closure technique with polypropylene No. 1 is better closure technique with low rate of wound infection and wound dehiscence as compared to continuous suturing technique with same suture material. ${ }^{4}$ The continuous suture has the advantages of an evenly distributed tension across the suture line and saves time. But it has a disadvantage that if pulled too tightly, it causes devascularization of the joint edges and if slack anywhere, it threatens the integrity of the whole line of approximation. For these reasons and others, interrupted sutures, although taking longer time to insert, are considered favourable. Moreover, interrupted (far - near near - far) is a tensionless suture, if loosely tied, prevents tissue necrosis.

The modified interrupted technique (far-near near-far), also known as Smead Jones technique, used in managing the patients with generalized peritonitis and metastatic abdominal tumours (complicated / high risk laparotomies) is associated with a low incidence of serious complications like wound dehiscence and incisional hernia formation comparable to other techniques. ${ }^{5}$

The results of Smead Jones technique of emergency midline closure of wound were compared with other conventional methods in a prospective study. $90 \%$ of the wounds were class IV and at high risk of wound complications. It was seen that the overall infection rate for Smead Jones technique was the lowest $(12.4 \%)$. Wound dehiscence rate with this technique was $3 \%$ at the lowest as compared to other types of closure ${ }^{6}$. The aim of the present study was to observe the occurrence of wound dehiscence in class III and class IV wounds, that is contaminated and dirty wounds respectively, with an interrupted far-near near-far technique (Smead Jones technique) of midline abdominal wound closure and to study the occurrence of wound dehiscence in patients requiring laparotomy and having high risk / co-morbid states who have more chances of wound dehiscence like malignancy, tuberculosis, renal failure, cirrhosis or any other immunosuppressed state.

\section{METHODS}

This study was conducted in the Department of Surgery, Government Medical College, Jammu over a period of one year starting from $1^{\text {st }}$ November 2015 till $31^{\text {st }}$ October 2016 and included patients admitted in the emergency department. A total number of 100 cases reported in the emergency over a period of one year's time were selected and abdominal wound closure was done by Smead Jones technique.

\section{Inclusion Criteria}

1. Generalized perforation peritonitis irrespective of the cause (class III or class IV wounds).

2. Patients undergoing laparotomy with co-morbid factors like malignancy, tuberculosis, diabetes mellitus, renal failure or any other immunosuppressed state.

\section{Exclusion Criteria}

1. Patients who had undergone elective laparotomy.

2. Patients who had undergone a previous laparotomy for any other condition.

All the cases planned for this study and who needed a laparotomy for generalized peritonitis or any other condition were admitted in emergency for diagnostic work up including a detailed history and clinical examination. Baseline investigations including complete blood count, renal function tests, serum electrolytes, blood sugar (random), blood group, ECG, chest x-ray, ultrasonography or any other relevant investigation were done. Patients who required laparotomy were subjected to proper resuscitation and pre-operative preparation before surgery was undertaken.

Under general anaesthesia, the operative field was cleaned with $10 \%$ povidone iodine and abdomen opened through a midline incision and the surgical procedure was performed according to the requirement of the underlying disease. After dealing with the primary pathology, a thorough peritoneal lavage was performed in all the cases. Adequate number of drains were kept in the peritoneal cavity. A modified repair of the midline abdominal wound was performed in all the cases using Smead Jones (far-near near-far) interrupted technique using polypropylene (Prolene 1 No.).

\section{Technique of Suturing}

The Smead Jones sutures (far-near near-far) are double far- 
near, near-far applied to linea alba. Suture is taken from outside in about $1 \mathrm{~cm}$ away (far) from edge of linea alba, then brought outside from the edge (near) of contralateral side through linea alba. Suture is again brought outside in through the edge (near) of linea alba through the ipsilateral side and then inside out away (far) from the edge of linea alba through the contralateral side and then tied.

All the patients were started on intravenous antibiotics. The wound was managed by daily antiseptic dressings. Postoperatively the patients were followed up daily for 10 days, then after a period of every 15 days up to 6 weeks to check for any disruption in suture line.

\section{Statistical Analysis}

Results were interpreted as proportions and were written as percentages. Analysis was performed in SPSS ver. 20.0 (IBM Inc.) and the significance was tested at $5 \%$ level.

\section{RESULTS}

All patients were operated in the emergency department under general anaesthesia. The incision used was vertical midline. Majority of the cases were perforation peritonitis and intestinal obstruction (malignant or tubercular) (Table 1). Out of 100 patients, 76 patients had dirty wound, 10 had contaminated and clean contaminated in 14 patients (Table 2).

\begin{tabular}{|ccc|}
\hline Final Diagnosis & No. of Cases & Percentage \\
Peptic ulcer perforation & 52 & $52 \%$ \\
Perforated appendix & 12 & $12 \%$ \\
Small gut perforation & 12 & $12 \%$ \\
Large gut perforation & 04 & $04 \%$ \\
Intestinal obstruction & 14 & $14 \%$ \\
GB perforation & 04 & $04 \%$ \\
Ruptured liver abscess & 02 & $02 \%$ \\
Total & $\mathbf{1 0 0}$ & $\mathbf{1 0 0} \%$ \\
\hline Table 1. Final Diagnosis of All Operated Cases $(\boldsymbol{n}=\mathbf{1 0 0})$ \\
\hline
\end{tabular}

\begin{tabular}{|ccc|}
\hline Type of Surgery & No. of Cases & Percentage \\
\hline Clean & 0 & $0 \%$ \\
Clean contaminated & 14 & $14 \%$ \\
Contaminated & 10 & $10 \%$ \\
Dirty & 76 & $76 \%$ \\
Total & 100 & $100 \%$ \\
\hline Table 2. Type of Surgery and Intra-Operative Findings \\
\hline
\end{tabular}

\begin{tabular}{|ccc|}
\hline Wound Status & No. of Patients & Percentage \\
Dehiscence & 02 & $2 \%$ \\
No dehiscence & 98 & $98 \%$ \\
Total & $\mathbf{1 0 0}$ & $\mathbf{1 0 0} \%$ \\
\hline \multicolumn{3}{|c|}{ Table 3. Wound Dehiscence Rate } \\
\hline
\end{tabular}

Out of 100 patients, 2 patients had wound dehiscence (Table 3). Dehiscence was observed on $7^{\text {th }}$ post-operative day in one patient who was a case of perforation peritonitis due to duodenal ulcer perforation presented late in emergency after four days of symptoms. Secondary suturing was done after proper build up and was discharged on $16^{\text {th }}$ post-operative day of his index surgery.

The other patient was a case of traumatic perforation of sigmoid colon presented in emergency after 36 hours of blunt trauma abdomen. Dehiscence was noted after $10^{\text {th }}$ post- operative day. Secondary suturing was done after proper build up and discharged on $24^{\text {th }}$ post-operative day of her index surgery.

\section{DISCUSSION}

A variety of abdominal closure techniques have evolved over the years. However, wound dehiscence remains a serious complication. In this study an attempt was made to observe the association of wound dehiscence with the technique of wound closure in patients having contaminated and dirty wounds (class III and Class IV) and having comorbid conditions associated. It was observed in the present study that the rate of wound dehiscence was significantly reduced by using modified interrupted technique of wound closure (Smead Jones technique). These findings were in association with the study done by Sivam NS, et $\mathrm{al}^{6}$ who showed that overall infection rate with Smead Jones technique was $12.4 \%$, significantly less than other types of closure. Wound dehiscence rate for Smead Jones at $3.0 \%$ was the lowest. Further Rahman et al, in their study found that $23.33 \%$ cases had abdominal wound dehiscence having acute ileal perforation ${ }^{7}$. Patients included in the study were all the highrisk cases prone for wound dehiscence. Modified Smead Jones technique was used to close the laparotomy wound in which only one patient reported partial dehiscence which was in coherence with the present study.

Most of the studies prefer continuous suture closure over the interrupted suture closure technique. This is firstly because the continuous method is less time consuming and secondly, the latter usually has tight tying which may lead to lowered wound strength, whereas the continuous method distributes tension equally all through the length of the wound. Whipple and Elliot, in their study found that tying the sutures tightly can result in tissue ischemia and necrosis. ${ }^{8}$

Poole and co-workers in their study reported greater incidence of burst abdomen using continuous suture technique when compared with the simple interrupted suture or figure of eight mattress suture. ${ }^{9}$ However no significant difference was found in the rate of wound dehiscence when the two techniques were compared in a study by Richard and colleagues. $^{10}$ Polydioxanone (PDS), an absorbable monofilament suture material is considered superior to both absorbable braided and non-absorbable suture for fascial closure as it is associated with lesser incision pain and suture sinus formation. However, there is a cost restraint factor when it comes to the practical use of PDS. Lastly, the technique of wound closure has a great impact on the outcome of the wound strength. Continuous suture technique has the property of distributing the strain all through the length of the wound whereas in case of an interrupted closure the tension is usually restricted to the individual suture loop.

Despite all of these recommendations for a continuous suture technique, we decided to use interrupted suture technique as a primary surgical method for the closure of midline abdominal wounds using polypropylene (Prolene). Prolene is freely available in our hospital supply. We considered those patients who were high risk cases for wound dehiscence following laparotomy like having perforation peritonitis, malignancy and simultaneously having comorbid 
conditions like anaemia, diabetes, shock, and hypoproteinaemia. In our study, out of 100 patients 52 patients were having perforation peritonitis. 2 (7.7\%) wound dehiscence cases were noted in this group who were having a presumptive preoperative diagnosis of perforation peritonitis and no dehiscence was noted in other cases where laparotomy was performed. Both the wounds were categorized as dirty wound. This shows that intra-abdominal sepsis plays an important role in delaying wound healing. Smith has mentioned that infection after clean abdominal procedures is uncommon and usually reflects either poor technique or cross infection. ${ }^{11}$ Badar Murtaza, et al. in their study used the Smead Jones technique of wound closure and found that ${ }^{5}$ out of 36 patients using this method of wound closure, 20 (55.55\%) had inflammatory/intra-abdominal sepsis, 8 (22.22 \%) had trauma, 7 (19.44\%) had neoplasia and 1 (2.77\%) had vascular aetiology. Only $1(2.77 \%)$ had partial wound dehiscence and $1(2.77 \%)$ developed incisional hernia. Wound infection was noted in 12 (33.33\%); 4 (11.11\%) experienced pain over the subcutaneously palpable knots and 3 (8.33\%) developed sinus due to knots. They concluded that this modified technique was far superior when used in patients with generalized peritonitis and advanced malignancies as compared to conventional closure techniques. These results were in consistence with our study as only 2 cases of wound dehiscence were observed in patients where Smead jones technique was used for suture closure.

\section{CONCLUSIONS}

Wound dehiscence is attributed to many factors. These factors are present in the patient, environment, operation theatre, and wards. Apart from other factors, technique in closure of contaminated and dirty wounds is important in the final outcome of emergency laparotomy. In such cases burst abdomen can be reduced using Smead Jones (far-near nearfar) interrupted technique of midline abdomen wound closure.

Patients should be stabilized in emergency before taking him to the operation theatre. Adequate resuscitation including correction of fluid and electrolyte imbalances and other comorbidities should be addressed and corrected prior to operation. Keeping in mind the high risk of dehiscence in high risk laparotomies involving contaminated and dirty wounds and its catastrophic complications, aseptic measures all through the course of surgery should be taken. Along with the above measures, interrupted Smead Jones technique of midline abdominal wound closure can play an important role in decreasing wound dehiscence.

Financial or Other Competing Interests: None.

\section{REFERENCES}

[1] Localio SA, Morgan ME, Hilton JW. The biological chemistry of wound healing; the effect of dl-methionine on the healing of wounds in protein-depleted animals. Surg Gynecol Obstet.1948;86(5):582-9.

[2] Shukla HS, Kumar S, Misra MC et al. Burst abdomen and suture material: a comparison of abdominal wound closure with monofilament nylon and chromic catgut. Indian J Surg 1981;43:487-91.

[3] Lewis RT, Wiegand FM. Natural history of vertical abdominal parietal closure: prolene versus dexon. Can J Surg 1989;32:196-200.

[4] Tariq M, Jamal A, Khan MA, et al. Comparison of two suturing techniques: interrupted mass closure and continuous mass closure with polypropylene in laparotomy wound. Pakistan Journal of Medical \& Health Sciences 2008;2(4):11.

[5] Murtaza B, Khan NA, Sharif MA, et al. Modified midline abdominal wound closure technique in complicated/high risk laparotomies. J Coll Physicians Surg Pak 2010;20(1):37-41.

[6] Sivam NS, Suresh S, Hadke MS, et al. Results of the Smead Jones technique of closure of vertical midline incisions for emergency laparotomies--a prospective study of 403 patients. Trop Gastroenterol 1995;16(4):62-7.

[7] Rahman M, Azad AS, Mawla MS, et al. Outcome of abdominal wound closure following continuous and interrupted suture in elective laparatomy. Faridpur Med Coll J 2013;8(2):73-6.

[8] Whipple AO, Elliott RH. The repair of abdominal incisions. Ann Surg 1938;108(4):741-56.

[9] Poole GV. Mechanical factors in abdominal wound closure: the prevention of fascial dehiscence. Surg 1985;97(6):631-40.

[10] Richards PC, Balch CM, Aldrete JS. Abdominal wound closure. A randomized prospective study of 571 patients comparing continuous versus interrupted suture techniques. Ann Surg 1983;197(2):238-43.

[11] Smith JAR. Wound infection. In: Kyle S, Smith D, Johnston P, eds. Pye's surgical handicraft. 22 ${ }^{\text {nd }}$ edn. Philadelphia: Butterworth Heinemann 1992: p. 111. 